\title{
Yeni Gençlik Kültürü ve Sosyal Sermaye: Hakkari İli Özelinde Bir Alan Araştırması
}

\author{
DOI: $10.26466 /$ opus. 845838 \\ *

\section{Yunus Eroğlu*} \\ * Öğr. Gör. Hakkari Üniversitesi, YMYO, Yönetim ve Organizasyon Bölümü, \\ Dr. Öğrencisi, Sakarya Üniversitesi, Sakarya/Türkiye \\ E-Posta: yunuseroglu@hakkari.edu.tr \\ ORCID: $\underline{0000-0002-6076-4868}$
}

\section{Öz}

Sosyal sermaye, son dönemlerde sosyal bilimler alanında skça tartışılan konu başlıklarından biri olmuştur. Özellikle ülkelerin gelişim süreçlerinde sosyal sermaye konusunun önemi anlaşılmış, tam ve eksiksiz bir büyüme için sosyal sermaye değerlerinin üzerine yoğunlaşmak gerekli görülmüştür. Sosyal sermaye; sosyal ilişkiler, sivil katılım, değerler, güven, aile bağları gibi kaynakları içerisinde barındırmaktadır. Hakkari kent merkezi özelinde gençlerin sosyal sermaye kaynaklarına ne derecede etki ettiğini ortaya koymayı hedefleyen bu çalışma; bölgenin sosyal dinamiklerini ortaya koyması bakımından da önem atfetmektedir. Özellikle küreselleşmenin büyük etkisiyle gençliğin dönüşümü gerçekleşmiş ve internet, sosyal medya ve sanal ortamlarm yaygınlık kazanmasiyla birlikte gençler arasında geleneksel ilişkiler yerini sanal ilişkilere bırakmıştır. Yaşanılan enformasyon çağında gençlerin toplumsal ilişkilerinin, toplumsal güven ve gönüllü katılım düzeylerinin değerlendirilmesi de bu çalışmanın amaçları arasındadır. Nitel araştırma metodunun tercih edildiğ i bu çalışma, mülakat veri toplama yöntemiyle verilerin saptanmasını amaç edinmiş olup bu çalışmanın kapsamında; küreselleşme ve sanal ortamlarla birlikte ortaya çıkan "yeni gençlik kültürü", sosyal sermayenin kavramsal analizi ve sosyal sermaye tartışmaları, Hakkari gençlerinin sosyal sermaye değerlerinin irdelenmesi ve bulguların analiz edilmesi yer almaktadır. Hakkari ilinde 18-24 yaş aralığındaki 10 katılımcıyla gerçekleştirilen yarı yapılandırılmış mülakat çalışmasının ele aldı̆̆ı değerlendirme düzeyleri ise genel anlamda toplumsal ilişkiler, sivil katılım, toplumsal güven ve güven çapıdır. Kartopu örneklem seçim tekniği ile belirlenmiş olan katılımcılardan elde edilen bulgular; yeni gençlik kültürü ve en önemli taşıyıcısı olan sosyal medya araçlarının sosyal sermayeye olumlu ve olumsuz anlamda etki ettiğini göstermektedir.

Anahtar Kelimeler: Sosyal Sermaye, Yeni Gençlik Kültürü, Hakkari, Sosyal Medya, Sosyal İlişkiler. 


\title{
New Youth Culture And Social Capital: A Field Research Based Upon Hakkarı Province
}

\begin{abstract}
Social capital has recently been become one of the most discussed topics in the field of social sciences. Especially in the economic development process of countries, it is argued that social capital comprising of social relations, civic participation, values, trust and family ties is necessary for full and solid growth. In this end, this study aims at revealing to what extent young people in the province of Hakkâri do affect the social capital resources, which also attaches importance to the social dynamics of the region.Traditional relations among young people have turned into virtual relations with the great influence of globalization and specifically with the widespread use of the internet, social media and virtual environments. Therefore, the social relations, social trust and the voluntary participation levels of the young from Hakkari in the information age are also in the scope of this paper.This study, in which the qualitative research method was preferred, aimed to determine the data with the interview data collection method, and within the scope of this study; "New youth culture" that emerged with globalization and virtual environments, conceptual analysis of social capital and social capital discussions, examining the social capital values of Hakkari youth and analyzing the findings. The evaluation levels of the semi-structured interview study conducted with 10 participants between the ages of 18-24 in Hakkari are generally social relations, civic participation, social trust and trust. The findings obtained from the participants determined by the snowball sampling technique; It shows that the new youth culture and its most important carrier, social media tools, have positive and negative effects on social capital.
\end{abstract}

Keywords: Social Capital, New Youth Culture, Social Media, Hakkari, Social Relations. 


\section{Giriş}

Günümüz modern yaşamın ve küreselleşmenin yaratmış olduğu haberleşme, sosyal medya, zaman ve mekan sınırlarının daha esnek hale gelmesi, özgürlük, insan hakları, yeni yaşam biçimlerinin tercih edilmesi gibi değerler söz konusudur. Hiç kuşkusuz küreselleşmenin yaymış olduğu bu değerlerden birincil düzeyde etkilenen gençlerdir. Gençlerin küreselleşme ile birlikte sanal ortamlarda bir araya gelmeleri, online oyun ve arkadaşlık sitelerinde sosyal ilişkiler geliştirmeleri, sosyal medyayı etkin bir biçimde kullanarak gerçek dünya ile sanal dünya arasında bir ağ oluşturmaları ve bu oluşan yeni değerler manzumesiyle davranış kalıpları sergilemesi "yeni gençlik kültürü" olgusunu yaratmaktadır. Pre-modern dönemde sosyalleşme modellerinin, iletişim formlarının, tüketim ve üretim tarzlarının günümüz dünyasından büyük oranda farklılık göstermesi, toplumsal ilişkilerinin ve toplumsal güven değerlerinin de müstesna olmasına sebebiyet vermiştir. Yeni gençlik hareketlerinin içinde barındırmış olduğu küresel değerler ve yeni gençlik kültürünün taşıyıcısı konumunda bulunan sosyal medya araçları, gençlerin sosyal sermaye rezerv ve biçimlerini de önemli derecede şekillendirmiştir. Yeni gençlik kültürünün; toplumsal ilişkilerin, yardımlaşma kültürünün, toplumsal güvenin, demokratik-siyasi katılımın ekonomik kalkınmaya destek sunması olarak tanımlayacağımız sosyal sermayeye bir takım tesirleri söz konusudur. Bu kontekste ele alınan bu araştırma, yeni gençlik kültürünün sosyal sermayeye ne derecede etki ettiğini saptamayı amaç edinmektedir.

\section{Yeni Gençlik Kültürü ve Sosyal Medya}

Birleşmiş Milletler'in 15-24 yaş aralığı olarak belirlediği gençlik, insan yaşamının farklı bir evresini oluşturduğu için biyoloji, etnografya, tarih, psikoloji ve sosyoloji gibi çeşitli bilim dallarının araştırma alanları arasında kendine yer bulmuştur. Biyolojik yaklaşım, gençteki psikolojik ve davranışsal değişikliklerin temel nedeninin biyogenetik faktörler olduğunu savunurken; etnografik yaklaşım ise bu değişikliklerin açıklanması için farklı kültürlerdeki varyasyonların incelenmesi gerekliliği üzerinde durmuştur. Tarihsel yaklaşımın bu değişimin açıklanması için öne sürdüğü argüman, gençlik kavramına atfedilen 
tanımın endüstri devrimiyle birlikte farklılaştığıdır. Psikolojik yaklaşım, gençlik dönemini etkileyen iç ve dış faktörlerin açıklanmasında ve değişmenin gençlik dönemi ile ilişkilendirilmesinde psikanalitik teori, sosyal psikoloji teorileri ve sosyal öğrenme teorilerinin çıkarsamalarına dikkat çekmektedir. Sosyolojik yaklaşım, gençlik döneminin belirleyicisi olarak sosyal çevre üzerinde durmaktadır. Sosyolojik yaklaşım teorilerine göre pre-endüstri döneminde genç ve yetişkinin aynı çatı altında yaşadığı ve benzer aktivite ve görevleri yerinde getirdiği; sanayileşme ve kentleşme olgularından sonra ise genç ve yetişkinlerin aktivite ve görevlerinin birbirinden ayrıldığ 1 ve yeni aile biçimlerinin ortaya çıtı $\breve{g} 1$ vurgulanmaktadır (Şahin, 2005, s.170).

Özellikle 1980'li yıllardan sonra gençliği konu edinen çalışmalarda gözle görülür bir artış yaşanmıştır. Toplumsal katılımlarını, yerel yönetimlere katılımlarını, eğitim ve istihdam gibi meseleleri konu edinen bu çalışmaların artışı, Birleşmiş Milletler 'in gençlik temalı çalışmaları ile paralellik göstermektedir. 1992 Rio de Janeiro Yeryüzü Zirvesi'nin Gündem 21'inin 25. bölümünde ele alınan sürdürülebilir kalkınma, 1996 yılında İstanbul'da düzenlenen konferansta Habitat II Gündem Belgesi ve 2001 yılında İstanbul+5 Konferans'ının gündem maddesini oluşturan gençlik çalışmaları, gençlik ve gençlerin yaşam standartlarının ulusal ve uluslararası belgelerde yer almasına katkı sunmuştur (Özer, 2011, s.45).

Yeni gençlik kültürü, 1980'li yıllardan başlayarak küreselleşmenin ve kitle iletişim araçlarının yaygınlaşmasının büyük etkisiyle gençlerin tüketim, iletişim, davranış tercihlerinin önceki kuşaktan farklılaşarak yeni bir suret kazanmasını ifade etmektedir. Yeni gençlik kültürünün ayırt edici unsurları; tüketime odaklı olmaları, özgürlüğe düşkün olmaları ve egosantrist davranış kalıplarına sahip olmalarıdır. Sosyal medyanın özelde birey ve toplumun tüm katmanlarında kendini takdim edebilme yetisi sonsuz ve sınırsız bir özgürlük mecrası iddiasından ileri gelmektedir. Bu doğrultuda içinde barındırdığı geçmişin özgürlükleri kısıtladığı algısı söz konusudur. Gençlerin sosyal medya araçları ve tatbikine sınır konulmaması gerektiği fikri, buradan ileri gelmektedir (Babacan, 2016, s.29). Yeni gençlik kültürü, bilgi-bilişim çağının en önemli araçları olan internet, sosyal medya, online (çevirim-içi) oyunlar ve eğlence programlarıyla yeni aktivite alanları ve davranış biçimleri yaratmaktadır. Bu dav- 
ranış biçimleri, sosyal alanların farklılaşmasıyla belirginlik kazanmaktadır. Sosyal alanların farklılaşması ile beraber klasik sosyalleşme biçimleri olan aile-mahalle içinde sosyalleşme yerini sanal mekanlarda sosyalleşmeye bırakmıştır. Yüz yüze gerçekleşen iletişim, yerini sanal mekanlarda çevirim-içi iletişime bırakmıştır.

2000'li yıllar itibariyle internetin kullanım alanının genişlemesi ve bununla birlikte yaşanan hızlı toplumsal değişim, gençlerin sosyalizasyon sürecini doğrudan etkilemiştir. Özellikle ebeveynlerle geçirilen zaman kısalmış ve anne-baba-öğretmenler gibi rol modeller yerini popüler kültürün yarattığ 1 modellere bırakmıştır. Ayrıca sosyal medyanın yaygınlık kazanmasıyla birlikte kendisini daha fazla ifade edebilme olanağına kavuşan gençler, iletişime geçebileceği birey sayısını arttırmış, duygu ve düşüncelerini büyük kitlelere ulaştırabilme fırsatı yakalamış, nicelik bağlamında klasik sosyalleşme biçimlerinin sosyalleşme olanağ sunduğundan daha fazlasına sahip olmuştur. Bu kontekste sosyal medya araçları gençlerin sosyalleşme biçim ve alanlarını değiştirse de gençlerin iletişim kanallarını çeşitlendirme, ulaştı̆̆ kitleyi attırma, gönüllü organizasyonlar, sivil toplum kuruluşları ve siyasi katılım hakkında bilgilendirme fırsatları sunmaktadır. Yeni gençlik kültürü araçları, gençleri bir yandan bireyselleştirirken diğer yandan toplumsallaştırmaktadır (İli, 2013, s.10). Kurumlar, organizasyonlar ve kuruluşların, tanıtım ve organizasyonları sanal mekanda afişe etmeleri, gençlerin bu organizasyonlardan haberdar olmalarına olanak sunmakta ve katılımlarını sınır tanımaksızın yapmalarına imkân tanımaktadır.

İletişim teknolojilerinin gelişimi ve tüm dünyaya erişim sağlayan iletişim ağları, tüm toplumların iletişim tercihlerini belirlemiş ve büyük bir yaygınlık kazanmıştır. Bu teknolojik gelişim, yeni jenerasyonların dikkatini daha fazla çekmekte ve yeni kuşağı önceki kuşaktan farklılaştırmaktadır. Bu farklılaşma iletişim teknolojilerini kullanma oranında, sosyalleşme tercihlerinde ve sosyal çevreyle kurulan ilişkilerin biçimlerinde görülmektedir. Kuşaklar arasında yabancılaşmaya neden olan sosyal medyanın bir diğer göstergesi iletişim dilidir. Daha çok zamana yayılmış ve uzunca bir arka plana sahip olan yetişkinlerin ilişkiiletişim diline karşılık sosyal medya dili anlık ve bağlamsız bir ilişkiiletişim biçimine dönüşmüştür (Babacan, 2016, s.33-34). 
İnternet ve sosyal medya hesapları, bu hesap kullanıcılarını belli bir kültüre davet ederken aynı zamanda iletişime ve etkileşime olanak veren yapısıyla da katılımcıların kendilerini yeniden tanımladıkları ve sanal ortamda sosyalleştikleri bir mekan olarak da dikkat çekmektedir. Özellikle internet sitelerinin chat (sohbet) odaları ve sosyal medya hesapları (Facebook, Instagram, Twitter, Youtube) katılımcıların kendilerine yeni mekanlar edinmelerine olanak sunmaktadır (Güzel, 2006, s.13). Böylelikle "yeni gençlik kültürü", gençleri aile-okul-mahalle gibi mekanlardan sanal mekanlara doğru itmektedir.

Küresel melez kültürün içinden doğan yeni gençlik kültürü, tüm dünya toplumlarında benzer özellikler taşımaktadır. Bu yaratılan kültürün beğenileri, refleksleri ve tutumları aynılaşmaktadır. Bu bağlamda değerlendirildiği takdirde yeni gençlik kültürünün en önemli taşıyıcı ayaklarını sosyal medyanın oluşturduğu görülmektedir. Bundan dolayıdır ki sosyal medyanın gençliği; dil, algı ve tutumlar bakımından etkilemesi kaçınılmaz hale gelmektedir. Kendini akıllı, yeni, özgürlükçü gibi vasıflarla takdim eden sosyal medyanın, gençlerin bağımlılığı üzerinden toplumsal derinliği zaafa uğratan ve toplumsal yapının ve ilişkilerin hasar görmesine neden olan bir yanı da bulunmaktadır. Sosyal medyanın bu menfi tarafı, sosyal sermaye birikimine de zarar vermektedir (Babacan, 2016, s.31). Fakat sosyal medyanın etkilerini tek taraflı olarak değerlendirmek, ulaşılabilecek sonucun yanıltıcı olmasına neden olacaktır. Özellikle sosyal medyanın, gençlerin büyük kitlelerle iletişim kurabilmesine olanak tanıyan, yardım organizasyonlarına ve demokratik kurumlara ulaşılabilirlik kazandıran yanı, sosyal sermayeye pozitif etki de yaratmaktadir.

\section{Sosyal Sermaye}

Sosyal sermaye kavramı, toplumsal ilişkiler, güven, siyasi katılım, gönüllülük gibi olguların kombinasyonuyla yaratılan, toplumsal yaşama olduğu kadar ekonomiye de katkı sunan bir kavramdır. Sosyal sermeye kavramının üzerinde konsensüs sağlanmış tek tanımı olmasa da Temple'ın kısa tanımıla; en az iki kişi arasında güvene dayalı bir şekilde kurulabilen iletişim imkanı, ya da biraz daha uzun bir tanımlamasıyla; toplumu 
oluşturan fertler, sivil toplum örgütleri ve kamu kurumları arasındaki koordinasyon faaliyetlerini kolaylaştırarak toplumun üretkenliğini arttıran, güven, norm ve iletişim ă̆ı özellikleri tanımı, kavramı daha anlaşılır kılmaktadır (Akt. Karagül ve Masca, 2005, s.39). Sosyal sermaye kavramının kökleri, Alexis de Tocquaville, Karl Marx, Emile Durkheim ve Max Weber'e kadar götürülse de bilinen ilk kullanımı Lyda Judsen Hanifan'a aittir. Hanifan 1916 yılında yaptığ 1 "The Rural School Community Center"adlı çalışmasında sermayenin salt ekonomik boyutunu değil aynı zamanda ona katkıda bulunan ve toplumsal bütünlüğü de sağlayan bireyler ve aileler arasında iyi niyet, arkadaşlık, sempati ve sosyal yakınlıkların varlığına dikkatleri çekmek için sosyal sermaye kavramını geliştirmiştir (Şan, 2011, s.93). İnterdisipliner bir kavram olan sosyal sermaye kavramının ne ifade ettiği ve hangi boyutlarıyla ele alındığını ortaya koyabilmek için Alexis de Tocquaville, Karl Marx, Pierre Bourdieu, Robert Putnam, Francis Fukuyama ve Samuel Coleman'ın çalışmalarına bakmak gerekmektedir.

Tocquaville, 1835 yılında kaleme aldığı "Democracy in America" adlı eserinde sosyal sermayenin önemine vurgu yapmaktadır. Amerika'nın göçmenler tarafından kurulan bir devlet olmasına rağmen ekonominin, demokrasinin ve siyasal sisteminin Avrupa ülkelerinin aksine nasıl bu denli geliştiğinin üzerinde duran Tocquaville, sosyal sermayenin Amerika'nın gelişimine katkısını bu sözlerle ifade etmektedir;

Amerikalılar, yaşlarl, sosyal durumları ve kültürleri ne olursa olsun hep birleşirler. Orda sadece, herkesin iştirak ettiğ i ticari ve sanayii cemiyetler değil, binlerce türlü cemiyet vardır: dini, ahlaki, ciddi, gayri ciddi, çok umumi, hususi, büyük, küçük her türlüsü. Amerikalllar bayramlar yapmak, seminerler tertip etmek, kiliseler tesis etmek, kitaplar neşretmek, dünyanın öbür ucuna misyonerler göndermek için birleşirler. Bu şekilde, hastaneler, hapishaneler ve okullar inşa ederler. Nihayet büyük bir örneğin desteğiyle bir hissi geliştirmek veya bir gerçeği ortaya koymak için birleşirler. Yeni tip teşebbüssün başında, Fransa'da hükümeti, Ingiltere'de büyük bir asili görebileceğiniz her yerde Amerika'da bir cemiyet görürsünüz (Tocquaville, 1962, s.82).

Karl Marx ise, sermayeyi toplumsal eşitsizliklerin merkezine yerleştirmektedir. Toplumsal eşitsizliklerin yaratılması ve bunun eşitsizlik yaratan bir bilinç ortaya çıkarması noktasında sermayenin önemini 
vurgulayan Marx, kapitalist toplum sisteminin iki ana karakteristik özelliği olarak sermaye ve yabancılaşma fikrini ortaya atmıştır (Aydemir, 2011, s.33).

Bourdieu'nun sosyal sermayeye yaklaşımı, gerçekte ve uygulamada karşılıklı tanı̧̧ılık veya tanımaya dayalı olarak az ya da çok kurumsallaşmış, uzun ömürlü iletişim ağına sahip olması dolayısıyla birey veya grubun hissesine düşen kaynakların toplamı şeklindedir. Ayrıca Bourdieu, sermayenin salt ekonomik teori tarafından değil bütün biçimlerinin etkisini kabul etmeksizin sosyal dünyanın anlaşılamayacağını belirtmektedir (Kitapçı, 2015, s.16). Bourdieu için sosyal sermaye, kişinin bir toplumsal alana katılımını ve katılımından sonraki bu alan içerisinde rekabetin getirdiği özel kazançlara ulaşmayı mümkün kılan bir kaynaktır. Bourdieu, sosyal sermayeyi ilk kez şöyle tanımlamıştır: "Gerekli olduğunda faydal "destekler" sağlayan toplumsal ilişkilerin sermayesi; herhangi biri toplumsal açıdan önemli konumlara, örneğin siyasi bir kariyer gibi aynı zamanda para değgri de olan konumlara, sahip olan müşterilerin ilgisini çekmek istediğinde çŏ̆u zaman vazgeçilmez olan sayginlığın ve onurluluğun sermayesidir" (Akt. Palabıyık, 2011, s.132). Bu bağlamda Bouedieu, sosyal sermayeyi, toplum içerisinde eşitsizlik yaratan bir kaynak olarak görmektedir. Sermaye kavramına; sınıfların eşitsizliğinin sürdürülmesinin bir aracı olarak bakan Bourdieu, kişinin bir toplumsal alanda kazanç sağlamak için mücadeleye giriştiği ve bu mücadele sonucunda da kazanç sağlamasını mümkün kılan aracın sosyal sermaye olduğunu düşünmektedir. Bu anlamda bireyin içerisinde bulunduğu toplumun "kimlik bilgisi", bireye belli kazanımlar sunmaktadır. Bir başka gruba dahil olan bireyden farklılaşmasının da temelini bu kimlik bilgisi yaratmaktadır. Bourdieu'nun yapmış olduğu bir başka tanımda sosyal sermaye; "yatırıma daha yüksek getiri sağlayarak rekabet avantajı sağlayan az ya da çok genişletilmiş, az ya da çok mobilize edilebilir bir ilişkiler ağı aracılığıyla aktive edilen kaynakların toplamıdır." (Bourdieu, 2005, s.194).

Max Weber, "Protestan Ahlakı ve Kapitalizmin Ruhu" isimli çalışmasında, ismi konulmasa da sosyal sermayenin üretkenliğe olan katkısına vurgu yapmıştır. Ekonomik kalkınmanın arkasında yatan temel unsurların kültürel ve dini değerler olduğunu vurgulayan Weber'e göre; bu değerleri, püriten etik oluşturmaktadır. Weber, rasyonel kapitalist sis- 
temin yaratılabilmesi için yeni bir çalışma etiğini içinde barındıran kültürel değerlerin temel belirleyici olarak ele alınması gerekliliği üzerinde durmuştur (Şan, 2006, s.3-4).

Robert Putnam, sosyal sermaye teorisini makro ölçekli göstergeler üzerinden inşa etmektedir. Bu anlamda etkin bir siyasal yönetimin geliştirilmesi ve sürdürülebilir ekonomik kalkınmanın sağlanması sosyal sermaye ile ilişkilendirilmiştir. Putnam'a göre modern dünyanın özgürlükçü sosyal politikalarından beslenen bireyselleşme eğilimi, toplumsal birlikteliği sağlayan sosyal sermaye kaynaklarını eritmektedir (Akt. Aydemir, 2011, s.63-64). 2000 yılında Robert Putnam tarafından kaleme alınan "Bowling Alone" eseri de bu minvalde bir başyapıttır. $\mathrm{Bu}$ eser, sosyal sermayenin Amerika coğrafyasında bireyselleşme ve rasyonelleşme ile birlikte erimeye başladığını konu edinmektedir.

Robert Putnam, sosyal sermaye tanımı yaparken fiziksel sermayeden ve beşeri sermayeden farklılaşan noktalarına temas etmiştir. Putnam, fiziksel sermayenin fiziksel nesnelere, insan sermayesinin bireysel özelliklere ve en nihayetinde sosyal sermayenin ise bireysel arasındaki bağlantılara, bunlardan kaynaklanan karşılıklılık ve güvenilirlik normalarına atıfta bulunduğunu ifade etmiş̧tir (Putnam, 2000, s.16). Putnam, sosyal sermayeyi ikili sınıflandırmayla ele almaktadır. Bunlar; bağlayıcı (bonding) sosyal sermaye ve köprü oluşturan (briging) sosyal sermayedir. Bağlayıcı sosyal sermaye, seçkin kimlikleri belirlemek ve homojenliği devam ettirme eğilimi göstermekteyken; köprü oluşturan sosyal sermaye ise çeşitli toplum grupları arasından insanları bir araya getirme eğilimi göstermektedir. Bağlayıcı sosyal sermaye; etnik ve milliyetçi gruplar, çeşitli kardeşlik organizasyonlardan insanların meydana getirdiği sosyal sermayedir. Bu gruplar arasında grup-içi güven duygusu ve sadakat yoğun olarak hissedilmektedir. Köprü oluşturan sosyal sermaye ise sivil haklar hareketleri ve gençlik grupları gibi daha yumuşak bağlarla bağlanan gruplar tarafından inşa edilebilmektedir (Aydemir, s.71).

Sosyal sermaye kaynağının en önemli kaynağının güven olduğunu savunan Francis Fukuyama, farklı ülke ve ulusların güven düzeyleri ile ekonomik performansları arasında bir mukayese yapmış ve bir toplumun güven düzeyinin; refahın ve demokrasinin koşullarını yapılandırdığı sonucuna varmıştır (Alacahan ve Duman, 2011, s.111). Sosyal değerleri; ahlaka ve güvene bağlı olarak açıklayan Fukuyama, toplum düzeninin bu 
değerlerle bezenmiş bir sivil toplumdan ileri geldiğini savunmaktadır. Ayrıca aile ve akrabalık ilişkilerinin de önemini vurgulayan Fukuyama, bu ilişkilerin ekonomik kalkınmaya önemli etkilerinin olduğunu dile getirmektedir. Ayrıca "Büyük Çözülme" çalışmasında aşırı bireycilik kültürünün, sosyal normlar alanına taşarak otorite unsurlarını aşındırdığını ve aileleri, mahalleleri ve ulusları bir arada tutan bağları zayıflattığını iddia etmektedir (Aydemir ve Tecim, 2012, s.47).

Samuel Coleman ise, Sosyal sermaye kavramına daha çok aile ve kilise üzerinden yaklaşmıştır. Sosyal sermaye rezervlerinin, bu kurumlardaki ağırlığına değinen Coleman, eğitimde öğrenci başarılarının aile içi sosyal ve beşeri sermayeye endeksli olduğunu vurgulamaktadır. Coleman, Amerika'da öğrencilerin okuldaki başarılarına ve okuldan ayrılma sebeplerine üç faktörün doğrudan etki ettiğini savunmaktadır. Bunlar; finansal sermaye, beşeri sermaye ve sosyal sermayedir. Bu faktörlerden finansal sermaye; çocuğun eğitsel başarısında gerekli olan ekonomik kaynağı , beşeri sermaye; ailenin çocuğun eğitim sürecine katkıda bulunacak derecede ebeveyn eğitim düzeyini, sosyal sermaye ise; aile içindeki yakın ilişkileri, ebeveyn-çocuk ilişkisi ve aile-okul ilişkilerini ifade etmektedir (Kitapçı, 2015, s.17).

\section{Yöntem}

Hakkari ilindeki 15-24 yaş arası olarak belirlenen genç nüfusun yeni gençlik kültüründen ne derecede etkilendiğini, yeni gençlik kültürünün temel taşıyıcıları olan sosyal medya araçlarını ne sıklıkla kullandıklarını ve yeni gençlik kültürünün Hakkari'deki gençlerin sosyal sermaye kaynaklarını nasıl etkilediğini saptamayı amaç edinen bu araştırma, yarı yapılandırılmış mülakat çalışmasıyla verilerin toplanmasını uygun bulmuştur. Kartopu örneklem tekniği ile 2018 yılının Ağustos ve Eylül aylarında 10 kişiyle yapılan mülakat görüşmesinin evreni, Hakkari ilindeki 15-24 yaş arası genç kitledir. Yapılan mülakat görüşmelerinde ses kayıt ve not alma tekniğinin birlikte uygulandığı bu araştırma verilerinin çözümlenmesinde Miles-Huberman analiz modeli kullanılmıştır.

Ayrıca belirtmekte fayda vardır ki bu araştırmanın nitel olarak tasarlanmasının altında yatan sebep, katılımcıların güven düzeylerinin, sosyal ilişkilerininin ve sivil katılımlarının nedenlerini derinlemesine irdelemek 
ve bireylerin içinde yaşamış oldukları dünya hakkında bir anlam arayışında olduklarını ortaya koymaktır. Diğer taraftan Dünya Değerler Araştırması'nın ve temaya ilişkin literatürdeki neredeyse tüm çalışmaların verilerinden hareketle; düşük seviyerde ölçülen Türkiye sosyal sermayesinin Hakkari ili bağlamında nedenlerini irdelemek, bireysel deneyimlere ulaşmak ve anlam dünyalarını keşfetmek bu araştırmanın nitel metoda başvurmasının temel motivasyonudur.

\section{Araştırmanın Amacı}

Yeni gençlik kültürünün en önemli taşıyıcılarından olan sosyal medya araçlarının sosyal sermayeye olan etkilerini irdelemek, bu araştırmanın birincil amacını oluşturmaktadır. Hakkari ili özelinde gençlerin toplumsal ilişkilerini, gönüllülük esaslı organizasyonlara ve sivil toplum kuruluşlarına katılımlarını, siyasi katılımlarını ve gerek kurumlara olan güvenlerini gerek toplumsal güven düzeylerini saptamak ve değerlendirmek bu araştırmanın bir diğer amacını oluşturmaktadır.

\section{Kartopu örneklem}

Araştırmanın örneklem metodunu oluşturan kartopu örneklem modeli, araştırmanın başında belirlenen bir olay veya bir deneğin araştırmacıya, ilişkili olay veya deneğe ulaşmasında kolaylık sağlamaktadır. Araştırma için benimsenen bu örneklem metodu, özellikle olay ve denek hususunda diğerlerini etkileyen kişilerin örneklem oluşturması için kullanılmaktadır.

\section{Yarı Yapılandırılmış Mülakat Çalışması}

$\mathrm{Bu}$ araştırmada elde edilen veriler genel literatürn tercih etmiş olduğu soruların özünden hareketle oluşturulmuş olan yarı yapılandırılmış mülakat formu üzerinden toplanmıştır. Soruların hazırlanması sürecinde açılık, anlaşılabilirlik, katılımcıların görüşlerini etkilememe gibi genel ilkelere dikkat edilmiş olup katılımcılara sorular aynı biçimde ve aynı tonlamalarla yöneltilmiştir. 


\section{Verilerin Analizi}

Verilerin analiz edilmesi sürecinde uygulanan model, Miles-Huberman modelidir. Bu model, verilerin düzenlenmesi-azaltılması, verilerin sergilenmesi ve sonuçların doğrulanması süreçlerini kapsamaktadır. Bu modelin öngördügü analiz sürecinin ilk aşaması olan verilerin azaltılması süreci; verilerin düzenlenmesi, gruplara ayrılması ve bölünmesi-özet çıkarılması adımlarından oluşmaktadır. Birinci aşamada yapılacak böyle bir düzenleme verilerin kodlanması sırasında meydana gelecek hata oranlarını minimum seviyeye çekecektir. Modelin ikinci aşaması; verilerin sunumu aşamasıdır. Bu aşamada, azaltılan verilere ilişkin bilgiler sıkıştırılır ve birleştirilir. Böylelikle veriler daha sistematik bir biçime dönüştürülmüş olur. Miles-Huberman veri analizi modelinin son aşaması ise sonuçların tasvir edilmesi ve doğrulanmasıdır. Bu safhada araştırmacı, çeşitli anlamlar oluşturma stratejilerini kullanır. Bu model, veri analizi yapan araştırmacı için somut gerçeklikten soyut ve genellenebilir kuram ve kavramlara ulaşma konusunda kolaylık sağlar ( Baltacı, 2017, s.4-9).

\section{Bulgular}

Sosyal medya araçları, hayatımızda önemli bir yer tutmaktadır. Özellikle gençler arasında yaygınlık kazanan bu mecra, kullanıcılara güven vermese de üyelik yapmada, veri paylaşmada ve verilerin tüketilmesi hususunda çekince yaratmayan bir duruş sergilemektedir. Katılımcılara sorulan "Sosyal medya araçlarına güveniyor musunuz ? sorusuna genel olarak "güvenmiyoruz" cevabı alınsa da üyelik yapılırken kişisel bilgilerin paylaşımında ve veri paylaşımında herhangi bir endişe, korku yaşamamaları dikkat çekicidir. Bu araştırmaya katılan 10 katılımcıdan sadece iki kişi sosyal medya araçlarını kullanmazken; nedenleri sorulduğunda ise; "sosyal medya araçlarına güvenmiyorum." ve "ders çalışmayı engelliyor ve aile ile olan iletişimi engelliyor." yanıtları alınmıştır. Ayrıca K-9 kullanıcısı, "sosyal medya araçlarına verilerimi girip kayıt yaptırırken güven problemi yaşıyorum ama bu beni yolumdan alıkoymuyor ve ilerdeki zararların pek fazla düşünemiyoruz, bağımlılık haline geliyor." Şeklinde çarpıcı bir yanıt vermiştir. K-1 kullanıcısı da sosyal medyaya olan güvensizliğini; "uygulamayı indirirken bu uygulama sizin bilgilerinize erişecektir gibi bir uyar veriyor ve bu 
durum benim hiç hoşuma gitmiyor. Sonuçta o uygulamanın esas bir yönetim merkezi vardır ve onlar benim bütün bilgilerime sahip olacaklar ama sanki mecburmuşuz gibi kayıt yaptırıyoruz." şeklinde dile getirmektedir. Bu bağlamda şu değerlendirme yapılabilir; sosyal medya, güvensizlik yaratan, gerçekdışı kabul edilen ama gerçekliğin buraya nakledildiği ve güvensizlik içinde yaşamaya mecbur kılan ve güvensizlik içinde yaşamayı öğreten bir mecradır. Gençlerin bir çoğu da bunu bu hailiyle kabul etmekte fakat ondan bağımsız da kalmamaktadırlar.

Yapılan araştırmada Hakkari'nin sosyo-ekonomik yapısı, kentin sahip olduğu coğrafi ve kentleşememe sorunsall, kentin STK, dernek ve gönüllü organizasyonlara ev sahipliği yapamaması gibi bir takım meseleler; gençlerin sosyal sermaye rezervlerine etki etmiştir. Fukuyama'nın sosyal sermaye çalışmasının merkezine yerleştirdiği "güven", 17-24 yaş aralığındaki Hakkarili gençler üzerinde yapılan araştırmada oldukça dikkat çekicidir.

Dünya Değerler Araştırması'nın verilerine göre oldukça düşük seviyede ölçülen Türkiye toplumunun güven düzeyi, Hakkari ili özelinde de kendini göstermiştir. Dünya Değerler Araştırması'nın 1990-1991 yılları arasında yapılan Türkiye araştırmasında \% 9,8 seviyelerinde, 1996 yılında yapılan araştırmasında \%6,5 seviyelerinde, 2010-2014 yılları arasında 60 ülkede yapılan araştırmasında ise 11,6 seviyelerinde ölçülen toplumsal güven düzeyinin (URL1), Hakkarili gençler arasında da oldukça düşük bir seviyede olduğu görülmektedir. Gençlerin toplumsal güven konusunda bu denli karamsar bir tablo çizmesi, genç kuşakların önceki sahip olmayan gençlerin içinde bulundukları bu menfi durum, önceki kuşakların yarattığ güvensizlik ortamından ve artan bireyselleşme eğiliminden kaynaklanmaktadır. Halk arasında sıklıkla zikredilen "bu devirde babana bile güvenme" deyimi, yeni nesil gençlerin kulağına küpe olmuş durumda. Bu kontekste artan bireyselleşme ve rasyonelleşmenin güvensizliğin en temel nedeni olsa da önceki neslin yeni jenerasyona güvensizlik aşıladığı sonucuna varılmıştır.

Tablo 1'deki verilerden de anlaşılacağ üzere, sosyal medya ile güven düzeyi arasında anlamlı bir ilişki bulunmamaktadır. Katılımcılardan K-7 ve K-8 sosyal medya hesabı kullanmıyor olmalarına rağmen insanlara gü- 
venmediklerini söylerken; 17 yaşında bir lise öğrencisi olan K-3 de gününün büyük bir bölümünü sosyal medyada geçirirken insanlara hatta yakın çevresine dahi güvenmediğini söylemiştir.

Tablo 1: Sosyal Medya İle Toplumsal İlişkiler ve Güven İlişkisi (Hakkari-2018).

\begin{tabular}{|c|c|c|c|c|c|c|}
\hline $\begin{array}{l}\text { Kat1- } \\
\text { limc1 }\end{array}$ & Yaş & $\begin{array}{l}\text { Eğitim } \\
\text { Durumu }\end{array}$ & Cinsiyet & $\begin{array}{l}\text { Sosyal } \\
\text { Medya Ile } \\
\text { Geçirilen } \\
\text { Süre (Dk.) }\end{array}$ & $\begin{array}{l}\text { Toplum- } \\
\text { sal İlişki- } \\
\text { ler(Ak- } \\
\text { raba- } \\
\text { Komşu- } \\
\text { Eş-Dost) }\end{array}$ & $\begin{array}{l}\text { Genel } \\
\text { Güven } \\
\text { Düzeyi }\end{array}$ \\
\hline K-1 & 24 & $\begin{array}{l}\text { Yüksek okul } \\
\text { mezunu }\end{array}$ & Erkek & 120 & Çok iyi & $\begin{array}{l}\text { İnsanlara güve- } \\
\text { niyorum. }\end{array}$ \\
\hline K-2 & 18 & Lise mezunu & Erkek & 60 & Çok iyi & $\begin{array}{l}\text { İnsanlara gü- } \\
\text { ven konusunda } \\
\text { temkinliyim. }\end{array}$ \\
\hline K-3 & 17 & Lise öğrencisi & Kadın & 720 & Kötü & $\begin{array}{l}\text { İnsanlara gü- } \\
\text { venmiyorum } \\
\text { (yakınıma } \\
\text { dahi). }\end{array}$ \\
\hline K-4 & 24 & Lisans mezunu & Erkek & 240 & Çok iyi & $\begin{array}{l}\text { İnsanlara gü- } \\
\text { ven konusunda } \\
\text { temkinliyim. }\end{array}$ \\
\hline K-5 & 23 & Lisans mezunu & Kadın & 90 & Kötü & $\begin{array}{l}\text { İnsanlara gü- } \\
\text { ven konusunda } \\
\text { temkinliyim. }\end{array}$ \\
\hline K-6 & 17 & Lise mezunu & Kadın & 120 & Çok iyi & $\begin{array}{l}\text { İnsanlara gü- } \\
\text { venmiyorum. }\end{array}$ \\
\hline K-7 & 21 & $\begin{array}{l}\text { Yüksekokul } \\
\text { mezunu }\end{array}$ & Erkek & kullanmiyor & İyi & $\begin{array}{l}\text { İnsanlara gü- } \\
\text { venmiyorum. }\end{array}$ \\
\hline K-8 & 23 & Lise mezunu & Kadın & kullanmiyor & Çok iyi & $\begin{array}{l}\text { İnsanlara gü- } \\
\text { venmiyorum. }\end{array}$ \\
\hline K-9 & 21 & $\begin{array}{l}\text { Üniversite } \\
\text { öğrencisi }\end{array}$ & Erkek & 300 & Çok iyi & $\begin{array}{l}\text { İnsanlara gü- } \\
\text { ven konusunda } \\
\text { temkinliyim. }\end{array}$ \\
\hline K-10 & 24 & Lise mezunu & Erkek & 60 & Çok iyi & $\begin{array}{l}\text { İnsanlara gü- } \\
\text { ven konusunda } \\
\text { temkinliyim. }\end{array}$ \\
\hline
\end{tabular}

Ayrıca 10 kişiyle yapılan mülakat çalışmasında sadece bir kişinin insanlara güven hususunda sorun yaşamaması, olayın vahametini gösteren bir başka unsurdur. Araştırmada, katılımcılara insanlara neden güvenmiyorsun? Sorusuna ise genel olarak neden güveneyim ki yanıtı verilmiştir. 
Katılımcılar tarafından verilen yanıtlar, katılımciların bu duruma, insanlara güven duymamanın normal olduğu ve güven duyanların sorgulanması gerektiği şeklinde yaklaştığını ortaya koymuştur.

$\mathrm{Bu}$ araştırmanın elde ettiği verilerden çıarılabilecek bir diğer bulgu ise, Hakkarili gençlerin toplumsal ilişkilerinin oldukça iyi bir noktada olduğudur. Gerek komşuluk ilişkileri gerek akrabalık ilişkileri gerek eş-dost ilişkileri; geleneksel akraba-komşuluk ilişkileriyle örtüşmektedir. Hakkari'de akrabalık bağları; bağlayıcı sosyal sermaye kaynağı olan aşiretçiliğin devam etmesi, kentin küçük olmasından dolayı herkesin birbirini tanıyor olması, modern çekirdek aile yapısının aksine geleneksel geniş aile modelinin işlevsel halde olması gibi sebeplerden dolayı insanları birbirine bağlayan ve sıcak ilişkilerin devam etmesini sağlayan en önemli unsurların başında gelmektedir. Ayrıca Hakkari'de sosyal aktivite imkanlarının sinırlı olması ve en büyük sosyal aktivite aracı olarak dügünlerin ön plana çıkması; tüm akraba-eş-dost-komşunun sürekli bir arada olmasına olanak sunan ve kendini yenileyen bir kaynak niteliğindedir.

Hakkarili gençler de bu toplumsal ilişkileri, akrabalık ve komşuluk bağlarını devam ettirme eğilimi göstermektedirler. Katılımclardan K-4, "Akraba ziyaretleri için bayram veya özel günleri beklemem, sık sık akraba ziyaretlerinde bulunurum. Mesela aşă̆ı mahallede akrabalarım var, biz merkez mahallede oturuyoruz akşamları canımız sıkılınca aşă̆ı mahalledeki akrabalarımızı ziyarete gidiyoruz" diyerek aslında akraba ziyaretlerinin bir sosyal aktivite aracı olarak kullanıldığını ortaya koymaktadır. Yine K-4, "akşamları yemek yapıp komşumuza götürürüz, onlar da bize getirir" şeklindeki ifadesiyle komşuluk ilişkilerinin sıcak olduğunu belirtmektedir. K-6 katılımcısına sorulan akraba ve komşularınızla görüşür müsünüz? sorusuna, "sık sık olmasa da üç günde bir görüşürüm" cevabını vermiştir. Üç günde bir yapılan akraba- komşuluk ziyaretleri, post-modern dönemde yüksek seviyede bir ilişki ağıyla eş değerdir. Ayrıca K-9 katılımcısı da "bizim buralarda bir şey pişirilirse birlikte yenilir" diyerek geleneksel komşuluk değerlerinin sürdürüldügüne ve komşular arasındaki birliktelik ruhunun yaşatıldığına dikkat çekmiştir. 
Tablo 2: Toplumsal Proje- Gönüllü Faaliyetlere Katılım ve Demokratik-Siyasi Katılim (Hakkari-2018).

\begin{tabular}{|c|c|c|c|c|}
\hline $\begin{array}{l}\text { Kat- } \\
\text { lımcı }\end{array}$ & Yaş & $\begin{array}{l}\text { Cinsi- } \\
\text { yet }\end{array}$ & $\begin{array}{l}\text { Toplumsal Proje- Gönüllü } \\
\text { Faaliyetlere Katılım }\end{array}$ & $\begin{array}{l}\text { Demokratik-Siyasi } \\
\text { Katılım }\end{array}$ \\
\hline K-1 & 24 & Erkek & $\begin{array}{l}\text { Ne sosyal hayatta ne de sanal or- } \\
\text { tamda gönüllü faaliyetlere katılma- } \\
\text { dım. }\end{array}$ & $\begin{array}{l}\text { Sadece sandığa gidiyo- } \\
\text { rum. }\end{array}$ \\
\hline K-2 & 18 & Erkek & $\begin{array}{l}\text { Ne sosyal hayatta ne de sanal or- } \\
\text { tamda gönüllü faaliyetlere katılma- } \\
\text { dım. }\end{array}$ & $\begin{array}{l}\text { Yaşımdan dolayı seçim- } \\
\text { lere katılmadım ama ka- } \\
\text { tılacağım. Parti ya da } \\
\text { STK üyeliğim yok. }\end{array}$ \\
\hline K-3 & 17 & Kadın & $\begin{array}{l}\text { Sosyal hayatta bireysel olarak gö- } \\
\text { nüllü faaliyette bulunurum ama sos- } \\
\text { yal medya üzerinden yapmam. }\end{array}$ & Yaş engelim var. \\
\hline K-4 & 24 & Erkek & $\begin{array}{l}\text { Ne sosyal hayatta ne de sanal or- } \\
\text { tamda gönüllü faaliyetlere katılma- } \\
\text { dım. }\end{array}$ & $\begin{array}{l}\text { Sadece sandığa gidiyo- } \\
\text { rum. }\end{array}$ \\
\hline K-5 & 23 & Kadın & $\begin{array}{l}\text { Sosyal hayatta yardım vakfına üyeli- } \\
\text { ğim var ve aktif olarak görev aldım } \\
\text { ama sanal ortamda gönüllü faali- } \\
\text { yette bulunmadım. }\end{array}$ & $\begin{array}{l}\text { Sadece sandığa gidiyo- } \\
\text { rum. }\end{array}$ \\
\hline K-6 & 17 & Kadın & $\begin{array}{l}\text { Sosyal hayatta gönüllü faaliyetlerde } \\
\text { bulunmadım ama sosyal medya ara- } \\
\text { cllığıyla gönüllü organizasyonlara } \\
\text { katılımım var. }\end{array}$ & Yaş engelim var. \\
\hline K-7 & 21 & Erkek & $\begin{array}{l}\text { Sosyal hayatta yardım vakfına üyeli- } \\
\text { ğim var ve aktif olarak görev aldım. } \\
\text { ama sanal ortamda gönüllü faali- } \\
\text { yette bulunmadım. }\end{array}$ & $\begin{array}{l}\text { Sadece sandığa gidiyo- } \\
\text { rum ( } 1 \text { defa gittim son- } \\
\text { raki seçimlere de katıl- } \\
\text { mayı düşünüyorum). }\end{array}$ \\
\hline K-8 & 23 & Kadın & $\begin{array}{l}\text { Ne sosyal hayatta ne de sanal or- } \\
\text { tamda gönüllü faaliyetlere katılma- } \\
\text { dım. }\end{array}$ & $\begin{array}{l}\text { Sadece sandığa gidiyo- } \\
\text { rum. }\end{array}$ \\
\hline K-9 & 21 & Erkek & $\begin{array}{l}\text { Yardım faaliyetlerini organizasyon- } \\
\text { lardan bağımsız ve gizli olarak yapı- } \\
\text { yorum. }\end{array}$ & Sandığa gittim. \\
\hline K-10 & 24 & Erkek & $\begin{array}{l}\text { Ne sosyal hayatta ne de sanal or- } \\
\text { tamda gönüllü faaliyetlere katılma- } \\
\text { dım. }\end{array}$ & $\begin{array}{l}\text { Seçimlere düzenli olarak } \\
\text { katılırım. }\end{array}$ \\
\hline
\end{tabular}

Gönüllü organizasyonlara katılım konusunda sosyal medyanın etkisinden rahatlıkla söz edilebilir. Her ne kadar katılımcılardan bir çoğu sosyal medya araçları vasıtasıyla gönüllü organizasyonlara ve yardım kuruluşlarına destek sağlamasa da farkındalık yaratması bakımından önem atfetmektedir. Özellikle hayvan hakları koruma dernekleri ve çevre koruma 
dernekleri Hakkarili gençlerin duyarlılığını arttırmıştır. K-9 katılımcısı, sosyal medya araçları üzerinden edindiği bilgiler ışığında fenomen hale gelmiş olaylara kayıtsız kalmadığını dile getirmiş ve daha duyarlı hale geldiğini savunmuştur. Yine K-1 katılımcısı, atanan ama güvenlik soruşturması henüz tamamlanmayan kişiler için Twitter üzerinden bir yardım organizasyonu başlatıldığını böylelikle bir farkındalık yaratıldığını fakat kendisinin güven problemi yaşamasından dolayı dahil olmadığını söylemiştir. Ayrıca K-1 katılımcısı, çevre ve hayvanları koruma derneklerinin yaptığı çalışmaları sosyal medya üzerinden takip ettiğini, olumlu bulduğunu fakat yine güven duymadığı için dahil olamadığını sözlerine eklemiştir. K-6 katılımcısı da sosyal medya üzerinden hayvan hakları ile ilgili imza kampanyası yapan bir organizasyona katıldığını dile getirmiştir.

Hakkari kentinde gönüllü organizasyon, STK, yardım kuruluşları ve derneklerinin nicel olarak düşük seviyelerde olması, Hakkarili gençlerin bu tür organizasyonlarda yer almalarına engel teşkil etmiştir. Sosyal medya hesapları üzerinden faaliyet gösteren organizasyonlar ise genel manada duyarlılık kazandırsa da katılım ve faaliyet konusunda beklenen seviyeye ulaşamamıştır. Katılımcıların sanal ortamda faaliyet gösteren organizasyonlara güven duymaması hiç kuşkusuz bunun en etkili nedenidir.

Demokratik-siyasi katılımın bir çok alternatifi olsa da bunlardan en yaygın olanları referandum ve seçime katılım, sivil toplum kuruluşlarına katılım, siyasi parti oluşumlarında yer almak, sivil itaatsizlik, genel greve çağrı gibi demokratik katılımlardır. Ahmet Taner Kışlalı, siyasal katılımın her toplumda farklı işlev ve amaçlarının olduğunu kimi zaman amaçlara ulaşmak için bir araç olduğunu kimi zamanda doğrudan bir araç olduğunu belirtmiştir. Ayrıca siyasal katılımın güçlü ve katılım yollarının açık olduğu toplumlarda toplumsal çatışmaların azalmakta olduğunu, yurttaşlık duygu ve davranışlarının daha güçlü olduğu hususunun üzerinde durmaktadır (Akt. Görgülü, 2018, s.5). Türkiye'de sivil itaatsizlik, grev, STK'lara katılım düşük seviyelerde olmasına karşın en büyük demokratik katılım olarak görülen seçimlere katılım ise oldukça yüksek seviyelerde ölçülmektedir. 2011 verilerine göre Türkiye, Avrupa Ekonomik İşbirliği Örgütü (OECD) ülkeleri arasında seçim katılım oranlarının en yüksek olduğu ikinci ülke konumundadır. Bu sıralamanın birinci sırasında Belçika 
yer alırken Türkiye 2. Sırada, İsveç ise 3. Sırada yer almaktadır. 2015 verilerinde ise Türkiye; Malta ve Belçika'dan sonra seçimlere katılım oranları sıralamasında üçüncü sırada gelmektedir. (OECD, URL2). Türkiye'nin yıllara göre seçimlere katılım oranları ise 3 . Tabloda olduğu gibidir.

Tablo 3. Türkiye'de seçmenlerin seçimlere katılım oranları

\begin{tabular}{ll}
\hline Seçim yılı & Katılim oran \% \\
\hline $\mathbf{1 9 9 1}$ & 83 \\
\hline $\mathbf{1 9 9 5}$ & 85 \\
\hline $\mathbf{1 9 9 9}$ & 87 \\
\hline $\mathbf{2 0 0 2}$ & 79 \\
\hline $\mathbf{2 0 0 7}$ & 84 \\
\hline $\mathbf{2 0 1 1}$ & 87 \\
\hline $\mathbf{2 0 1 5}$ & 85 \\
\hline $\mathbf{2 0 1 8}$ & 87 \\
\hline
\end{tabular}

Kaynak: Yüksek Seçim Kurulu (YSK), URL3.

Araştırmanın verileri de katılımcıların seçimlere ilgili olduklarını göstermektedir. Tablo 2'den de anlaşılacağı üzere araştırmaya katılan gençlerden Türkiye'deki seçim yaşı olan 18'i tamamlayanlar, sandığa gittiklerini ve sonraki seçimlerde de sandığa gitmeye devam edeceklerini düşündüklerini belirtirlerken; henüz seçim yaşına ulaşmayanlar ise 18 yaşından sonra seçimlere katılacaklarını ifade etmişlerdir. Gençlerin, en demokratik hak olan seçimlere ilgili olmaları ülkenin demokratik katılımı açısından büyük önem atfetmektedir. Fakat, STK gibi siyasi parti gibi oluşumlara minimum seviyede destek vermeleri sadece Hakkari için değil; ülke genelinde kaygı verici bir durum yaratmaktadır.

\section{Tartışma ve Sonuç}

Hakkari ili özelinde yapılan bu çalışmanın bulgularından hareketle yeni gençlik kültürü ve onun en önemli taşıyıcısı olan sosyal medya, gençlerin sosyal sermaye kaynaklarına doğrudan ve dolaylı olarak tesir etmektedir. Yeni gençlik kültürünün yarattığı bireyselleşmenin gençlerin insanlara duydukları güveni önemli derecede etkilediği gözlemlenirken; Hakkarili gençlerin sosyal ilişkilerine ise çok fazla tesir edemediği görülmektedir. 
Hakkarili gençlerin sosyal ilişkilerinin modern aile-komşulukakrabalık ilişkileri motiflerinden farklılık göstermesine neden olan en önemli unsur; "aşiretçilik" gibi toplumları bir arada tutan doğal örgütlenme biçiminin önemini koruması ve Hakkari'nin sosyal anlamda "kentleşme" olgusundan uzak olmasıdır. Daha çok mahalle-köy kültürünün hakim olduğu Hakkari'de gençlerin birbirlerine duydukları güvensizlik ise genel manada içselleşen bireyselleşme ve rasyonelleşme eğiliminden kaynaklanmaktadır. Toplumsal çıkarların yerini bireysel çıkarlara bıraktığı modern ve post-modern dönemde Hakkari ilindeki gençler de bu dalgadan nasibini almışlardır. Komşuluk ilişkileri-akrabalık bağlarının güçlü olduğu bir toplumda güven probleminin yaşanması, güven çapının kendi iç-grubuyla sınırlı olduğunu göstermektedir. Bu kontekste Hakkarili gençler her ne kadar güven duymadıklarını belirtseler de kendi iç gruplarında bir güven çemberi oluşturmuş fakat bu çemberin çapını daraltmışlardır. 
EXTENDED ABSTRACT

\title{
New Youth Culture and Social Capital: A Field Research Based upon Hakkari Province \\ *
}

\author{
Yunus Eroğlu \\ Sakarya University
}

Social capital has been one of the topics that have been frequently discussed in the field of social sciences recently. Especially in the development processes of countries, the importance of social capital has been understood, and it has been deemed necessary to focus on social capital values for a full and complete growth. Social capital; It includes resources such as social relations, civic participation, values, trust, family ties. This study, which aims to reveal the extent to which young people affect social capital resources in Hakkari city center; It attaches importance in terms of revealing the social dynamics of the region. Especially with the effect of globalization, the transformation of youth has taken place and with the widespread use of internet, social media and virtual environments, traditional relationships among young people have been replaced by virtual relationships. Evaluating the social relations, social trust and voluntary participation levels of young people in the information age we live in is also among the aims of this study. In this study, in which the qualitative research method was preferred, within the scope of this study, which aimed to determine the data with the interview data collection method; "new youth culture" that emerged with globalization and virtual environments, conceptual analysis of social capital and social capital discussions, examining the social capital values of Hakkari youth and analyzing the findings. The evaluation levels of the semi-structured interview study conducted with 10 participants between the ages of 18-24 in Hakkari are generally social relations, civic participation, social trust and trust. The findings obtained from the participants determined by the snowball sampling technique; It shows that the new youth culture and social media tools, which are the most important carriers, have a positive and negative effect on social capital. The global values embodied in the new youth movements and the social media tools, which are the carriers of the new youth culture, have also shaped the social capital reserves and forms of the youth to a great extent. The new youth culture; There are some effects on social capital, which we can define as the support of social relations, cooperation culture, social trust, democratic-political participation to economic development.

Based on the data obtained from this study, the most important factor that causes the social relations of young people from Hakkari to differ 
from the modern family-neighborhood-relative relations motifs; The fact that the natural form of organization that holds societies together, such as "tribalism", preserves its importance and Hakkari is far from the phenomenon of "urbanization" in the social sense. In Hakkari, where the neighborhood-village culture is dominant, the distrust of young people towards each other is generally due to the internalization and rationalization tendency. In the modern and post-modern era, where social interests are replaced by individual

interests, young people in Hakkari have also received their share from this wave. The fact that there is a trust problem in a society with strong neighborly relations and kinship ties shows that the diameter of trust is limited to its own in-group. In this context, although the young people of Hakkari state that they do not trust, they have created a circle of trust in their inner group, but they have narrowed the diameter of this circle. Based on the findings of this study conducted in Hakkari province, the new youth culture and social media, which is its most important carrier, directly and indirectly affects the social capital resources of the youth. While it is observed that the individualization created by the new youth culture significantly affects the trust of young people in people; It is seen that it does not affect the social relations of young people from Hakkari very much.

In terms of participation in voluntary organizations, the effect of social media can be easily mentioned. Although many of the participants do not provide support to voluntary organizations and charities through social media tools, they attach importance to raising awareness. Especially animal rights protection associations and environmental protection associations have increased the sensitivity of Hakkari youth. The K-9 participant, one of the participants of the research, stated that he did not remain indifferent to the events that have become phenomenal in the light of the information he obtained through social media tools and argued that he became more sensitive. Another participant, the K-1 participant, said that an aid organization was started on Twitter for the people who were appointed but whose security investigation was not yet completed, thus creating an awareness, but he was not included because he had a trust problem. In addition, the K-1 participant added that he followed the work of the environmental and animal protection associations on social media, found it positive, but could not be included because he did not have confidence. The K-6 participant also stated that he participated in an organization that made a petition about animal rights on social media.

The quantitatively low levels of voluntary organizations, NGOs, aid organizations and associations in Hakkari prevented young people from Hakkari from taking part in such organizations. Organizations operating through social media accounts, on the other hand, have not reached the expected level in terms of participation and activity, although they have 
gained awareness in general terms. Undoubtedly, the most effective reason for this is that the participants do not trust the organizations operating in the virtual environment.

Another finding that can be deduced from the data revealed by this research is that the social relations of young people from Hakkari are at a very good point. Neighborhood relations, kinship relations, and peerfriend relations; coincides with traditional kin-neighbourhood relationships. Kinship ties in Hakkari; The continuation of tribalism, which is a binding source of social capital, the fact that everyone knows each other due to the small size of the city, and the fact that the traditional extended family model is functional in contrast to the modern nuclear family structure is one of the most important elements that connect people and ensure the continuation of warm relations. In addition, the limited social activity opportunities in Hakkari and the weddings coming to the fore as the biggest social activity tool; It is a self-renewing resource that allows all relatives-wife-friends-neighbors to be together constantly.

\section{Kaynakça / References}

Alacahan, O. ve Duman, B. (2011). Güven ve sivil bağlllık boyutuyla sosyal sermaye ve mezhep: Kahramanmaraş örneği. Elektronik Sosyal Bilimler Dergisi, 10 (36), 108-131.

Altunay, E., Oral, G., Yalçınkaya, M. (2014). Eğitim kurumlarında mobbing uygulamalarına ilişkin nitel bir araştırma. Sakarya University Journal Of Education, 4(1), 62-80.

Aydemir, M.A. (2011). Sosyal sermaye: Topluluk duygusu ve sosyal sermaye araştırması.(1. Baskı). Konya: Çizgi Kitabevi.

Aydemir, M.A., Tecim, E. (2012). Türk toplumunda aile ve dinin sosyal sermaye potansiyeli. Selçuk Üniversitesi Sosyal Bilimler Enstitüsü Dergisi, 28, 43-59.

Babacan, M.E. (2016). Toplumsal derinlik, sosyal medya ve gençlik. İnsan Ve Toplum Dergisi, 6(1), 23-45.

Baltacl, A. (2017). Nitel veri analizinde Miles-Huberman Modeli, Ahi Evren Üniversitesi Sosyal Bilimler Dergisi, 3(1), 1-15.

Bourdieu, P. (2005). The social structures of the economy. (Translated by Chris Turner), Cambridge: Polity Press.

Görgülü, B. (2018). Gençlerin siyasal katılım sürecinde sosyal medyanın rolü. Yayımlanmamış Yüksek Lisans Tezi. Selçuk Üniversitesi, Sosyal Bilimler Enstitüsü.

Güzel, M. (2006). Küreselleşme, internet ve gençlik kültürü. Küresel İletişim Dergisi,1, 1-16. 
İli, K. (2013). Sosyal medya ortam ve araçlarının öğrenci davranışlarına etkisi (Gazi çiftliği anadolu lisesi örneği). Yayımlanmamış Yüksek Lisans Tezi. Hacettepe Üniversitesi, Sosyal Bilimler Enstitüsü.

Karagül, M., Masca, M. (2005). Sosyal sermaye üzerine bir inceleme. Ekonomik Ve Sosyal Araştırmalar Dergisi, 1, 37-52.

Kitapçı, İ. (2015). Motivasyonel bir güç olarak sosyal sermaye kavramı ve rasyonalitesi. Hukuk Ve İktisat Araştırmaları Dergisi, 7(1-2), 11-36.

Özer, Y.E. (2011). Gençlerin toplumsal yaşama katılımı ve yerel yönetimlerin rolü. Dokuz Eylül Üniversitesi İktisadi Ve İdari Bilimler Dergisi, 26(1), 4365.

Palabıyı, A. (2011). Pierre Bourdieu sosyolojisinde "Habitus", "Sermaye" ve “Alan” üzerine. Liberal Düşünce Dergisi, 16(61-62), 121-141.

Putnam, R. D. (2000). Bowling alone: The collapse and revival of American community. Newyork: Simon\&Schuster.

Şahin, M.C. (2005). Türkiye'de Gençliğin toplumsal kimliği ve popüler tüketim kültürü. Gazi Eğitim Fakültesi Dergisi, 25(2), 157-181.

Şan, M.K., Şimşek, R. (2011). Sosyal sermayenin tarihsel-sosyolojik arka planı. Akademik Incelemeler Dergisi, 6(1), 88-110.

Şan, M.K. (2006). Bilgi toplumuna geçişte sosyal sermayenin taşıdığ Türkiye gerçeği. 5. Uluslararası Bilgi, Ekonomi Ve Yönetim Kongresi, Bildiri Kitabı, 1, 113-140.

Tocguaville, A. (1962). Amerika'da demokrasi. (Çev. T. Timur). Türk Siyasi İlimler Derneği Yayınları Siyasi İlimler Serisi: 4, İstanbul: Yenilik Basımevi. (Eserin orijinali 1835 yılında yayımlandı).

URL1, World values survey, 13.08.2018 tarihinde http://www.worldvaluessurvey.org/WVSOnline.jsp adresinden erişilmiştir.

URL2, OECD, 12.08.2018 tarihinde https://www.oecd.org/els/family/CO 42 Participation first time voters.pdf adresinden erişilmiştir.

URL3, Yüksek Seçim Kurulu, 11.08.2018 tarihinde http://www.ysk.gov.tr/tr/milletvekili-genel-secim-arsivi/2644 adresinden erişilmiştir. 


\section{Kaynakça Bilgisi / Citation Information}

Eroğlu, Y. (2021). Yeni gençlik kültürü ve sosyal sermaye: Hakkari ili özelinde bir alan araştırması. OPUS-Uluslararası Toplum Araştırmaları Dergisi, 17(38), 5186-5209. DOI: 10.26466/opus.845838 